\author{
HUMANASE SOCIAIS \\ V.8・N.3 $2020 \cdot$ Fluxo Contínuo \\ ISSN Digital: 2316-3801 \\ ISSN Impresso: 2316-3348 \\ DOI: 10.17564/2316-3801.2020v8n3p121-135
}

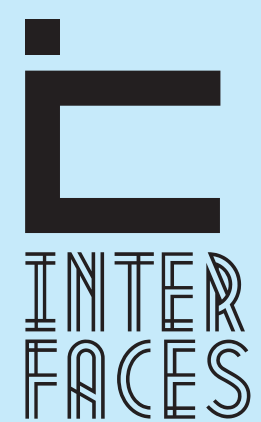

CIENTÍFICAS

\title{
EVIDENCIAÇ̃̃O DE INFORMAÇ̃̃ES SOCIOAMBIENTAIS POR ENTIDADES BANCÁRIAS PARTICIPANTES DA CARTEIRA DO ÍNDICE DE SUSTENTABILIDADE EMPRESARIAL - ISE
}

EVIDENCE OF SOCIO-ENVIRONMENTAL INFORMATION BY BANKING ENTITIES PARTICIPATING IN THE ISE CORPORATE SUSTAINABILITY INDEX PORTFOLIO

EVIDENCIA DE INFORMACIÓN SOCIOAMBIENTAL POR ENTIDADES BANCARIAS QUE PARTICIPAN EN LA CARTERA DEL ÍINDICE DE SOSTENIBILIDAD CORPORATIVA ISE

Neila Aparecida dos Santos Figueredo ${ }^{1}$

Thaysi Castro Coelho Andrade ${ }^{2}$

Cássia Regina de Lima ${ }^{3}$

Adriano Barreira de Andrade ${ }^{4}$

\section{RESUMO}

Este trabalho de pesquisa teve como finalidade analisar a evidenciação de informações socioambientais por entidades bancárias participantes da carteira do Índice de Sustentabilidade Empresarial (ISE), em conformidade com a NBC T-15. Buscou-se como objetivo investigar se as principais informações sociais e ambientais divulgadas das Demonstrações contábeis de três entidades bancárias listadas no ISE, Banco Santander, Banco do Brasil e Banco Bradesco, atendem as orientações da NBC T-15, as empresas receberam instruções para realizar a evidenciação de suas demonstrações contábeis em seus relatórios anuais. Cumprindo com suas responsabilidades diante de uma sociedade cada dia mais exigente, deixando claro seus interesses por investir em entidades que não buscam apenas o lucro financeiro, mas que se preocupam com a sustentabilidade. A natureza da pesquisa foi qualitativa, quanto aos objetivos, estes foram de forma exploratória e descritiva. Sobre o procedimento metodológico, utilizou-se a pesquisa documental para a coleta de dados no período de 2015 a 2017. Em relação aos resultados obtidos, segundo as informações disponibilizadas pelos bancos, concluiu-se que, de forma geral, os quesitos foram atendidos em sua maioria. Os investimentos sociais e ambientais estão presentes em seus relatórios, demonstrando de forma significada e positiva o poder de influência que estas três entidades bancárias possuem em relação a sociedade e ao meio ambiente.

\section{PALAVRAS-CHAVE}

Sustentabilidade. Balanço Social. NBC T-15. 


\section{ABSTRACT}

This research aims to analyze the disclosure of social and environmental information by banking entities participating in the portfolio of the Corporate Sustainability Index (ISE), in accordance with NBC T-15. The objective was to investigate whether the main social and environmental information disclosed in the Financial Statements of three banking entities listed in the ISE, Banco Santander, Banco do Brasil and Banco Bradesco comply with NBC T-15 guidelines. disclosure of its financial statements in its annual reports. Fulfilling its responsibilities to an increasingly demanding society, making clear its interests by investing in entities that do not only seek financial profit, but which are concerned with sustainability. The nature of the research was qualitative, regarding the objectives, these were exploratory and descriptive. On the methodological procedure, the documentary research was used for data collection in the period from 2015 to 2017 . In relation to the results obtained, according to the information provided by the banks, it was concluded that, in general, the questions were answered in their majority. Social and environmental investments are present in their reports demonstrating in a significant and positive way the power of influence that these three banking entities have in relation to society and the environment.

\section{KEYWORDS}

Sustainability. Social Balance. NBC T-15.

\section{RESUMEN}

Este trabajo de investigación tuvo como objetivo analizar la divulgación de información socioambiental por parte de las entidades bancarias que participan en la cartera del Índice de Sostenibilidad Corporativa (ISE), de acuerdo con NBC T-15. El objetivo era investigar si la principal información social y ambiental divulgada en los estados financieros de tres entidades bancarias que figuran en el ISE, Banco Santander, Banco do Brasil y Banco Bradesco, cumplen con las pautas de NBC T-15, las empresas recibieron instrucciones para llevar a cabo La divulgación de sus estados financieros en sus informes anuales. Cumplir sus responsabilidades frente a una sociedad cada vez más exigente, dejando en claro sus intereses en invertir en entidades que no solo buscan ganancias financieras, sino que se preocupan por la sostenibilidad. La naturaleza de la investigación fue cualitativa, en cuanto a los objetivos, estos fueron exploratorios y descriptivos. En cuanto al procedimiento metodológico, se utilizó la investigación documental para recopilar datos de 2015 a 2017. Con respecto a los resultados obtenidos, de acuerdo con la información proporcionada por los bancos, se concluyó que, en general, las preguntas se cumplieron en la mayoría Las inversiones sociales y ambientales están presentes en sus informes, lo que demues- 
tra de manera significativa y positiva el poder de influencia que estas tres entidades bancarias tienen en relación con la sociedad y el medio ambiente.

\section{PALABRAS CLAVE}

Sostenibilidad, Informe social, NBC T-15.

\section{INTRODUCÇÃO}

A busca pelo crescimento econômico e financeiro do homem tem causado impacto negativo no âmbito social e ambiental, gerando discussão em meio a sociedade que vem desenvolvendo interesse no assunto com o objetivo de conscientizar a população sobre os danos já causados e os futuros. Desastres ambientais estão acontecendo com certa frequência em diversas partes do mundo. $\mathrm{Na}$ cidade de Mariana com o rompimento da barragem da mineradora Samarco que destruiu a cidade e, recentemente houve um novo rompimento desta vez na cidade de Brumadinho, também no Estado de Minas Gerais, onde o prejuízo social e ambiental superou o de Mariana.

Diante de acontecimentos, surge o problema de pesquisa e objetivo, que pretende buscar se as principais informações socioambientais divulgadas das Demonstrações contábeis de três entidades bancárias, listadas no ISE, atendem as orientações da NBC T-15. E os objetivos específicos em (1) conhecer os aspectos teóricos acerca das informações socioambientais do índice de sustentabilidade e a NBC T-15, (2) comparar as informações socioambientais das empresas do setor financeiro pertencentes ao ISE, (3) verificar se as empresas do setor financeiro, pertencentes ao ISE divulgam suas informações conforme as orientações da NBC T-15.

O Conselho Federal de Contabilidade aprovou a NBC T-15 que dispõe sobre procedimentos técnicos para a evidenciação de informações voltadas para o social e ambiental. As informações divulgadas possibilitam aos investidores da bolsa de valores a tomarem suas decisões, bem como atende outros stakeholders, como fornecedores, clientes, governo, entre outros. Com a criação da carteira do ISE, é possível identificar quais empresas estão adotando a sustentabilidade como estratégia para novos negócios, pois quem investe em ações deseja obter lucros no longo prazo com empresas duradouras no mercado.

Em relação à relevância social e acadêmica busca-se esclarecer melhor sobre a responsabilidade e contribuição do profissional contábil junto as entidades quanto a contabilidade social e ambiental.

\section{METODOLOGIA}

A pesquisa realizou-se de forma qualitativa, pois busca a formação de um conjunto de dados para a evidenciação das demonstrações contábeis anuais que estejam em conformidade com a NBC T-15 e demonstrar quais as principais informações socioambientais divulgadas de três entidades bancárias listadas no ISE. 
Quanto ao objetivo metodológico, a pesquisa se deu de forma exploratória e descritiva, pois existe a necessidade em se fazer novas descobertas buscando novas explicações por meio da análise dos dados reunidos sobre o assunto proposto e descrever a evidenciação na elaboração das demonstrações contábeis. Serão utilizadas fontes primárias por meio de pesquisas em sites e artigos.

Gerhardt e Silveira (2009, p. 68) ressaltam que "pesquisas descritivas são realizadas com o intuito de descrever as características do fenômeno".

Quanto ao procedimento metodológico, foi usada a pesquisa documental para a obtenção dos dados. Por meio de sites, home page e correios eletrônicos disponibilizados na internet e que façam parte do domínio das empresas selecionadas para o estudo. Diante dos avanços da tecnologia, a tendência sugere que mais empresas adotem essa postura, tendo o governo como um dos grandes incentivadores.

Quanto ao local, realizou-se no Centro Universitário Luterano de Palmas (CEULP ULBRA). Com endereço na Avenida Joaquim Teotônio Segurado, 1501 Sul, Palmas-TO. Seu período foi de 2019.1, do curso de graduação em Ciências Contábeis. Quanto a localidade dos Bancos estudados, o Santander tem sua sede localizada em São Paulo/SP, o Banco do Brasil em Brasília/DF e o Bradesco em Osasco/SP.

Quanto ao objeto de estudo, surgiu a necessidade de evidenciar as informações das Demonstrações contábeis e do Balanço Social pertencentes as entidades bancárias, pois algumas empresas deixam de elaborar de forma correta, motivadas pela falta de fiscalização, descumprimento da norma por parte da empresa, ou a falta de informação pelo contador. O período a ser analisado teve início no ano de 2015 e encerramento no ano de 2017.

A população escolhida para o processo de análise e que farão parte do trabalho são empresas de capital aberto listadas na Comissão de Valores Mobiliários (CVM) e pertencentes a carteira do ISE. A participação na referida carteira depende de alguns fatores relevantes. As empresas participantes devem responder a um questionário e obedecer a norma que atua sobre a sustentabilidade, pois, por meio do mercado de capitais muitas empresas estão captando novos recursos financeiros com investidores interessados em participar de ações que tenham durabilidade no mercado e retorno no longo prazo.

Quanto a amostra da pesquisa, as empresas que fizeram parte da análise foram três entidades bancárias, sendo elas, o Banco Santander, Banco do Brasil e Banco Bradesco S/A. Todas estão listadas na CVM e participantes da carteira do ISE que atua com interesse voltado para a sustentabilidade.

O interesse pelas entidades bancárias se dá pelo fato de pertencerem ao grupo de empresas do ISE, empresas de grande porte e alta rentabilidade, estão localizadas em diversos lugares pelo Brasil e consequentemente atingindo um grande número de clientes e fornecedores que possuem muitos funcionários de diversas faixas etárias com raças e cores diferentes e ocupando muitos prédios consumindo insumos como água, energia e papel.

\section{RESULTADOS E DISCUSSÃO}

São apresentados a seguir os dados coletados durante o processo de análise do Balanço Social das empresas selecionadas. Preferiu-se apresentar os dados a partir das Instituições Financeiras.

Interfaces Científicas - Aracaju • V.8 • N.3 - p. 121-135 • 2020 • Fluxo Contínuo 
Inicialmente será demonstrado os dados do Banco Santander, em seguida do Banco do Brasil e finalmente do Banco Bradesco. Acerca da classificação de cada critério direcionado pela NBC T-15, utilizou-se as seguintes categorias, conforme o nível de adequação da empresa: Atende, Não atende ou Atende parcialmente.

\subsection{INFORMACÕES A SEREM DIVULGADAS CONFORME A NBC T - 15 DO BANCO SANTANDER}

Quadro 1 - Geração e Distribuição de Riqueza

\begin{tabular}{|c|c|c|c|}
\hline Períodos pesquisados & $\mathbf{2 0 1 5}$ & $\mathbf{2 0 1 6}$ & $\mathbf{2 0 1 7}$ \\
\hline $\begin{array}{c}\text { 15.2.1.1 - A riqueza gerada e distribuída } \\
\text { pela entidade deve ser apresentada con- } \\
\text { forme a Demonstração do Valor Adiciona- } \\
\text { do, definida na NBC T 3. }\end{array}$ & Atende & Atende & Atende \\
\hline
\end{tabular}

Fonte: Dados da pesquisa (2019).

O Banco Santander possui uma missão definida como banco e como parte da sociedade. Contribui com o progresso das pessoas e das empresas presentes no País por meio da prestação de serviços financeiros, da geração de valor aos seus acionistas e funcionários, também do investimento em iniciativas sociais e culturais.

Sobre a Demonstração de Valor Adicionado, sua apresentação no ano de 2015 foi de forma clara, elaborada, obedecendo a NBC T 3. Além da planilha contendo os números, apresentou também um demonstrativo com os percentuais referentes a cada item. No ano de 2016 a apresentação seguiu os moldes do ano anterior, obedecendo a planilha e o demonstrativo com os percentuais. Para o ano de 2017, as informações não foram apresentadas como nos anos anteriores.

Quadro 2 - Recursos Humanos

\begin{tabular}{|c|c|c|c|}
\hline Períodos pesquisados & 2015 & 2016 & 2017 \\
\hline $\begin{array}{c}\text { 15.2.2.1 - Devem constar dados referentes } \\
\text { à remuneração, benefícios concedidos, } \\
\text { composição do corpo funcional e as } \\
\text { contingências e os passivos trabalhistas da } \\
\text { entidade. }\end{array}$ & $\begin{array}{c}\text { Atende } \\
\text { Parcialmente }\end{array}$ & $\begin{array}{c}\text { Atende } \\
\text { Parcialmente }\end{array}$ & $\begin{array}{c}\text { Atende } \\
\text { Parcialmente }\end{array}$ \\
\hline
\end{tabular}

Fonte: Dados da pesquisa (2019).

Sobre o item 15.2.2.1 referente à remuneração do corpo funcional e passivos trabalhistas, os relatórios dos anos 2015, 2016 e 2017 atenderam de forma parcial ao quesito apresentado. Quanto aos quesitos do item 15.2.2.2, o ano de 2015 atendeu a 3 de um total de 13. Os que não atenderam foram 7 e apenas 1 atendeu parcialmente. Em 2016 houve uma pequena alteração, 4 quesitos foram atendi- 
dos, 6 não atenderam e 3 atenderam parcialmente. E em 2017, os que atenderam foram 4, os que não atenderam foram 6 e os que atenderam parcialmente totalizaram 3.

Nas informações relativas às ações trabalhistas contidas no item 15.2.2.5, os quesitos foram classificados como "não atende", pois deixou de informar os dados necessárias nos três anos pesquisados. Na sequencia o item 15.2.2.6 também não atendeu à solicitação e seu relatório deixou de evidenciar as informações.

Quadro 3 - Interação da Entidade com o Ambiente Externo

\begin{tabular}{|c|c|c|c|}
\hline Períodos pesquisados & $\mathbf{2 0 1 5}$ & $\mathbf{2 0 1 6}$ & $\mathbf{2 0 1 7}$ \\
\hline $\begin{array}{c}\text { 15.2.3.1 - Nas informações relativas à } \\
\text { interação da entidade com o ambiente } \\
\text { externo, devem constar dados sobre o re- } \\
\text { lacionamento com a comunidade na qual } \\
\begin{array}{c}\text { a entidade está inserida, com os clientes e } \\
\text { com os fornecedores, inclusive incentivos } \\
\text { decorrentes dessa interação. }\end{array}\end{array}$ & $\begin{array}{c}\text { Atende } \\
\text { Parcialmente }\end{array}$ & $\begin{array}{c}\text { Atende } \\
\text { Parcialmente }\end{array}$ & $\begin{array}{c}\text { Atende } \\
\text { Parcialmente }\end{array}$ \\
\hline $\begin{array}{c}\text { 15.2.3.4 - Nas informações relativas aos } \\
\text { fornecedores, a entidade deve informar se } \\
\text { utiliza critérios de responsabilidade social } \\
\text { para a seleção de seus fornecedores. }\end{array}$ & Atende & Atende & Atende \\
\hline
\end{tabular}

Fonte: Dados da pesquisa (2019).

O banco, falando sobre a interação com a comunidade no item 15.2.3.2, demonstra que seu relacionamento com as comunidades locais abrange todo território nacional, incluindo mais de 34 mithões de consumidores, uma equipe com mais de 47 mil funcionários e mais de 1.400 fornecedores. Dos cinco quesitos apresentados, o banco atendeu a três deles. Somente dois quesitos não foram atendidos, sendo saúde e alimentação.

As informações relatadas sobre a interação com os clientes, constantes no item 15.2.3.3, demonstra que dos seis quesitos apresentados, durante os anos de 2015, 2016 e 2017, quatro atenderam as normas e apenas dois não atenderam. Conforme dados do banco Santander, ele possui uma Diretoria de Satisfação de Clientes que, além de monitorar todas as reclamações de clientes e gerar alertas para uma rápida ação de organização, investe recursos em estratégias para garantir a satisfação dos seus consumidores.

Em se tratando da utilização de critérios para a seleção de fornecedores, o item 15.2.3.4 demonstra que o relatório atendeu aos três anos pesquisados. Em 2015 relatou sobre o compromisso de sustentabilidade junto aos fornecedores, incluindo respaldo contratual de cláusulas alinhadas às diretrizes do Pacto Global.

Em 2016 informou que durante a prestação de serviço realizada, é feito o monitoramento de seus fornecedores para verificar a regularidade das obrigações fiscais, tributárias e trabalhistas. E em 
2017 destacou que seus fornecedores precisam se comprometer com o cumprimento de obrigações socioambientais e concorda com o Código de conduta de fornecedores.

\subsection{INFORMACÕES A SEREM DIVULGADAS CONFORME A NBC T - 15 DO BANCO DO BRASIL}

Quadro 4 - Geração e Distribuição de Riqueza

\begin{tabular}{|c|c|c|c|}
\hline Períodos pesquisados & $\mathbf{2 0 1 5}$ & $\mathbf{2 0 1 6}$ & $\mathbf{2 0 1 7}$ \\
\hline $\begin{array}{c}\text { 15.2.1.1 - A riqueza gerada e distribuída } \\
\text { pela entidade deve ser apresentada con- } \\
\text { forme a Demonstração do Valor Adiciona- } \\
\text { do, definida na NBC T 3. }\end{array}$ & Atende & Atende & $\begin{array}{c}\text { Atende } \\
\text { Parcialmente }\end{array}$ \\
\hline
\end{tabular}

Fonte: Dados da pesquisa (2019).

Segundo dados apresentados pela entidade, o Banco do Brasil ocupa a posição de maior instituição financeira da América Latina em ativos, que somavam R\$ 1,51 trilhão em dezembro de 2015. Criado em 1808, o BB é uma empresa de economia mista controlada pela União e faz parte do Novo Mercado, listada na BM\&FBOVESPA que reúne as companhias com melhores práticas em governança corporativa. Com a missão de ser um banco de mercado com espírito público, possui a maior rede de atendimento brasileiro no Brasil e exterior.

A Estrutura do relatório foi elaborada de forma ampla e seus assuntos distribuídos de forma clara, obedecendo a ordem dos tópicos. Foram utilizadas principalmente as cores representadas pela bandeira do banco, amarelo e azul, porém houve a presença do preto. As letras, tamanhos de fontes e gráficos utilizados atenderam a necessidade para um bom entendimento das informações

Sobre a Demonstração de Valor Adicionado, sua apresentação no ano de 2015 foi de forma clara e objetiva, contou com a utilização de pequenos gráficos que ajudaram na visualização dos dados, obedecendo a NBC T 3. No ano de 2016 a apresentação seguiu os moldes do ano anterior, 2015, e também atendeu as normas de contabilidade.

Em 2017, houve mudança em sua apresentação. As informações não foram apresentadas como nos anos anteriores, foram utilizadas figuras que lembravam a tela de um aparelho de celular e seus aplicativos. Percebeu-se o interesse em incentivar o uso da tecnologia mobile como forma de acesso as contas. 
Quadro 5 - Recursos Humanos

\begin{tabular}{|c|c|c|c|}
\hline Períodos pesquisados & 2015 & 2016 & 2017 \\
\hline $\begin{array}{l}\text { 15.2.2.1 - Devem constar dados referentes } \\
\text { à remuneração, benefícios concedidos, } \\
\text { composição do corpo funcional e as con- } \\
\text { tingências e os passivos trabalhistas da } \\
\text { entidade. }\end{array}$ & Atende & $\begin{array}{l}\text { Atende } \\
\text { Parcialmente }\end{array}$ & $\begin{array}{c}\text { Atende } \\
\text { Parcialmente }\end{array}$ \\
\hline $\begin{array}{c}\text { 15.2.2.5 - Nas informações relativas às } \\
\text { ações trabalhistas movidas pelos em- } \\
\text { pregados contra a entidade, devem ser } \\
\text { evidenciados: }\end{array}$ & ------- & -------- & ------ \\
\hline $\begin{array}{l}\text { número de processos trabalhistas movidos } \\
\text { contra a entidade; }\end{array}$ & $\begin{array}{l}\text { Não } \\
\text { Atende }\end{array}$ & Atende & $\begin{array}{l}\text { Não } \\
\text { Atende }\end{array}$ \\
\hline $\begin{array}{l}\text { número de processos trabalhistas julga- } \\
\text { dos procedentes; }\end{array}$ & $\begin{array}{l}\text { Não } \\
\text { Atende }\end{array}$ & Atende & $\begin{array}{l}\text { Não } \\
\text { Atende }\end{array}$ \\
\hline $\begin{array}{l}\text { número de processos trabalhistas julgados } \\
\text { improcedentes; }\end{array}$ & $\begin{array}{l}\text { Não } \\
\text { Atende }\end{array}$ & Atende & $\begin{array}{l}\text { Não } \\
\text { Atende }\end{array}$ \\
\hline $\begin{array}{l}\text { valor total de indenizações e multas pagas } \\
\text { por determinação da justiça. }\end{array}$ & $\begin{array}{l}\text { Não } \\
\text { Atende }\end{array}$ & $\begin{array}{l}\text { Não } \\
\text { Atende }\end{array}$ & $\begin{array}{l}\text { Não } \\
\text { Atende }\end{array}$ \\
\hline $\begin{array}{l}\text { 15.2.2.6 - Para o fim desta informação, os } \\
\text { processos providos parcialmente ou encer- } \\
\text { rados por acordo devem ser considerados } \\
\text { procedentes. }\end{array}$ & $\begin{array}{l}\text { Não } \\
\text { atende }\end{array}$ & $\begin{array}{l}\text { Não } \\
\text { Atende }\end{array}$ & $\begin{array}{l}\text { Não } \\
\text { Atende }\end{array}$ \\
\hline
\end{tabular}

Fonte: Dados da pesquisa (2019).

A princípio o item 15.2.2.1, dados referentes à remuneração do corpo funcional e passivos trabalhistas, atendeu de forma parcial em sua maioria aos anos pesquisados. Porém, havia outras informações relevantes que contribuíram para a elaboração do relatório. A remuneração segregada, item 15.2.2.2, durante os três períodos, 2015, 2016 e 2017 atendeu em sua maioria aos quesitos apresentados.

A classificação "não atende", que não houve relatos do assunto e os demais atenderam parcialmente por mencionar os fatos relevantes. Portanto o item 15.2.2.3 onde solicita expressar em valor monetário as informações, obteve a classificação "atende parcialmente" ou "não atende" por não responder conforme a norma. 
Quanto a composição dos recursos humanos, 15.2.2.4, em sua maioria os quesitos foram classificados como "atende". Em se tratando da faixa etária, passou a ser “atende parcialmente", pois as idades não são as mesmas apresentadas no relatório. Nas informações de ações trabalhistas (15.2.2.5), - Banco do Brasil relata que participa das negociações de coletivas com a Confederação Nacional dos trabalhadores em Empresas de Crédito e a Confederação Nacional dos Trabalhadores no Ramo Financeiro.

Quadro 6 - Interação da Entidade com o Ambiente Externo

\begin{tabular}{|c|c|c|c|}
\hline Períodos pesquisados & $\mathbf{2 0 1 5}$ & $\mathbf{2 0 1 6}$ & $\mathbf{2 0 1 7}$ \\
\hline $\begin{array}{c}\text { 15.2.3.1 - Nas informações relativas à inte- } \\
\text { ração da entidade com o ambiente externo, } \\
\text { devem constar dados sobre o relacionamen- } \\
\text { to com a comunidade na qual a entidade } \\
\text { está inserida, com os clientes e com os } \\
\text { fornecedores, inclusive incentivos decorren- } \\
\text { tes dessa interação. }\end{array}$ & Atende & $\begin{array}{c}\text { Atende } \\
\text { Parcialmente }\end{array}$ & $\begin{array}{c}\text { Atende } \\
\text { Parcialmente }\end{array}$ \\
\hline $\begin{array}{c}\text { 15.2.3.4 - Nas informações relativas aos } \\
\text { fornecedores, a entidade deve informar se } \\
\text { utiliza critérios de responsabilidade social } \\
\text { para a seleção de seus fornecedores. }\end{array}$ & Atende & Atende & Atende \\
\hline
\end{tabular}

Fonte: Dados da pesquisa (2019).

Nas informações relativas à interação da entidade com o ambiente externo, item 15.2.3.1, o Banco do Brasil relata que as relações com funcionários, fornecedores, parceiros, clientes, credores, acionistas, concorrentes, comunidade, governo e entidades ligadas ao meio ambiente são pautadas pela ética, respeito e transparência. Observados os direitos trabalhistas, princípios de cuidados com o meio ambiente e valores universais de direitos humanos.

A entidade informa no item 15.2.3.4 que seus fornecedores são selecionados por meio de processo licitatório, conforme a Lei 13.303/2016 (Lei das Estatais) e de seu Regulamento de Licitações e Contratos. Em todos os processos de compra, os fornecedores devem se manifestar formalmente os compromissos sociais e ambientais. 0 termo de responsabilidade socioambiental registra o compromisso contratual dos fornecedores com a entidade. Item atendido nos três anos pesquisados. 
Quadro 7 - Interações com o Meio Ambiente

\begin{tabular}{|c|c|c|c|}
\hline Período pesquisados & 2015 & $\mathbf{2 0 1 6}$ & $\mathbf{2 0 1 7}$ \\
\hline $\begin{array}{c}\text { 15.2.4.1 - Nas informações relativas à in- } \\
\text { teração da entidade com o meio ambiente, } \\
\text { devem ser evidenciados: }\end{array}$ & -- ---- & - ------ \\
\hline $\begin{array}{c}\text { investimentos e gastos com manutenção } \\
\text { nos processos operacionais para a melhoria } \\
\text { do meio ambiente; }\end{array}$ & Atende & $\begin{array}{c}\text { Atende } \\
\text { Parcialmente }\end{array}$ & Atende \\
\hline $\begin{array}{c}\text { investimentos e gastos com a preser- } \\
\text { vação e/ou recuperação de ambientes } \\
\text { degradados; }\end{array}$ & Atende & $\begin{array}{c}\text { Atende } \\
\text { Parcialmente }\end{array}$ & $\begin{array}{c}\text { Atende } \\
\text { Parcialmente }\end{array}$ \\
\hline
\end{tabular}

Fonte: Dados da pesquisa (2019).

Nas informações relativas à interação com o meio ambiente, item 15.2.4, a entidade informa sua atuação por meio de tecnologias sociais desenvolvidas e aplicadas pela Fundação Banco do Brasil nas comunidades. Produtos, técnicas ou metodologias replicáveis que visam solucionar demandas como educação, energia, saúde e meio ambiente dentre outras.

Foi possível observar que nos três anos pesquisados, em sua maioria, os quesitos foram atendidos. A classificação "atende parcialmente" remete as ações relatadas executadas e as metas futuras planejadas pela entidade que estão sendo desenvolvidas. Por exemplo, estruturar modelo de captação de recursos, gestão e investimento em negócios sociais de alto impacto social e ambiental.

Informações a serem divulgadas conforme a NBC T-15 do Banco Bradesco S/A

Quadro 8 - Geração e Distribuição de Riqueza

\begin{tabular}{|c|c|c|c|}
\hline Períodos pesquisados & 2015 & 2016 & 2017 \\
\hline $\begin{array}{c}\text { 15.2.1.1 - A riqueza gerada e distribuída } \\
\text { pela entidade deve ser apresentada con- } \\
\text { forme a Demonstração do Valor Adiciona- } \\
\text { do, definida na NBC T 3. }\end{array}$ & Atende & Atende & $\begin{array}{c}\text { Não } \\
\text { Atende }\end{array}$ \\
\hline
\end{tabular}

Fonte: Dados da pesquisa (2019). 
Segundo dados apresentados pelo Bradesco, ao longo do tempo a entidade vem aprimorando o processo de elaboração de seu relatório. A partir de 2013 passou a publicar de maneira integrada, unindo os aspectos institucionais, de operações, de negócios e financeiros com a iniciativa de sustentabilidade. Em 2014 incorporou os aspectos propostos pela estrutura de relato integrado desenvolvida pelo International Integrated Reporting Council (IIRC), ou Conselho Internacional para Relato Integrado, a fim de elaborar de forma efetiva a integração das informações.

Sobre a Demonstração de Valor Adicionado, sua apresentação no ano de 2015 foi de forma clara elaborada, obedecendo a NBC T 3. As informações estão bem distribuídas, foram expostos comentários sobre os tópicos com a utilização de pequenos gráficos que ajudaram na visualização dos dados. No ano de 2016 a apresentação seguiu os moldes do ano anterior, 2015, também atendeu as normas de contabilidade. Para o ano de 2017, houve mudança em sua apresentação e as informações não foram apresentadas como nos anos anteriores.

Quadro 9 - Recursos Humanos

\begin{tabular}{|c|c|c|c|}
\hline Períodos pesquisados & $\mathbf{2 0 1 5}$ & $\mathbf{2 0 1 6}$ & $\mathbf{2 0 1 7}$ \\
\hline $\begin{array}{c}\text { 15.2.2.1 - Devem constar dados referentes à } \\
\text { remuneração, benefícios concedidos, compo- } \\
\text { sição do corpo funcional e as contingências e } \\
\text { os passivos trabalhistas da entidade. }\end{array}$ & $\begin{array}{c}\text { Atende } \\
\text { Parcialmente }\end{array}$ & $\begin{array}{c}\text { Atende } \\
\text { Parcialmente }\end{array}$ & $\begin{array}{c}\text { Não } \\
\text { Atende }\end{array}$ \\
\hline $\begin{array}{c}\text { 15.2.2.3 - Estas informações devem ser } \\
\text { expressas monetariamente pelo valor total } \\
\text { do gasto com cada item e a quantidade de } \\
\text { empregados, autônomos, terceirizados e } \\
\text { administradores beneficiados. }\end{array}$ & $\begin{array}{c}\text { Atende } \\
\text { Parcialmente }\end{array}$ & $\begin{array}{c}\text { Atende } \\
\text { Parcialmente }\end{array}$ & $\begin{array}{c}\text { Não } \\
\text { Atende }\end{array}$ \\
\hline
\end{tabular}

Fonte: Dados da pesquisa (2019).

Conforme as informações relatadas pelo Banco Bradesco no item 15.2.2.1 onde devem constar a remuneração, benefícios concedidos, composição do corpo funcional e as contingências e os passivos trabalhistas da entidade, não foram evidenciados conforme a norma. Nos anos de 2015 e 2016 foram classificados como "atende parcialmente", pois não forneceram a informação completa. E no ano de 2017 houve apenas um breve comentário reduzido, sendo classificado como "não atende".

As informações apresentadas no item 15.2.2.3 que devem ser expressas monetariamente pelo valor total de cada gasto, tiveram a classificação "atende parcialmente" nos anos de 2015 e 2016 por não obedecer de forma clara as normas. Em 2017 foram feitos comentários sobre a atuação da entidade, porém deixou de atender como deveria. 
Quadro 10 - Interação da Entidade com o Ambiente Externo

\begin{tabular}{|c|c|c|c|}
\hline Períodos pesquisados & $\mathbf{2 0 1 5}$ & $\mathbf{2 0 1 6}$ & $\mathbf{2 0 1 7}$ \\
\hline $\begin{array}{c}\text { 15.2.3.1 - Nas informações relativas à } \\
\text { interação da entidade com o ambiente } \\
\text { externo, devem constar dados sobre o re- } \\
\text { lacionamento com a comunidade na qual } \\
\begin{array}{c}\text { a entidade está inserida, com os clientes e } \\
\text { com os fornecedores, inclusive incentivos } \\
\text { decorrentes dessa interação. }\end{array}\end{array}$ & $\begin{array}{c}\text { Atende } \\
\text { Parcialmente }\end{array}$ & $\begin{array}{c}\text { Atende } \\
\text { Parcialmente }\end{array}$ & $\begin{array}{c}\text { Atende } \\
\text { Parcialmente }\end{array}$ \\
\hline $\begin{array}{c}\text { 15.2.3.4 - Nas informações relativas aos } \\
\text { fornecedores, a entidade deve informar se } \\
\text { utiliza critérios de responsabilidade social } \\
\text { para a seleção de seus fornecedores. }\end{array}$ & Atende & Atende & Atende \\
\hline
\end{tabular}

Fonte: Dados da pesquisa (2019).

O Banco Bradesco possui em sua lista de clientes, seis públicos prioritários que exercem ou sofrem influência nos seus negócios: clientes, público interno, acionistas e investidores, fornecedores, governo e comunidade, sociedade e terceiro setor. No item 15.2.3.1 é possível verificar que a empresa atendeu de forma parcial ao quesito, pois foram apresentadas propostas de projetos, porém não apresentou clareza nas informações.

Com relação ao item 15.2.3.4, a Empresa utiliza critérios de responsabilidade social e ambiental para a seleção de seus fornecedores. Fatores como a não utilização de trabalho infantil e forçado ou análogo ao escravo, além da gestão de saúde e segurança ocupacional e da gestão ambiental e social. Pode ser observada essa informação nos três anos pesquisados, 2015, 2016 e 2017, atendendo assim ao pré-requisito da norma.

Quadro 11 - Interações com o Meio Ambiente

\begin{tabular}{|c|c|c|c|}
\hline Período pesquisados & $\mathbf{2 0 1 5}$ & $\mathbf{2 0 1 6}$ & $\mathbf{2 0 1 7}$ \\
\hline $\begin{array}{c}\text { 15.2.4.1 - Nas informações relativas à in- } \\
\text { teração da entidade com o meio ambiente, } \\
\text { devem ser evidenciados: }\end{array}$ & $\begin{array}{c}\text { Atende } \\
\text { Parcialmente }\end{array}$ & $\begin{array}{c}\text { Atende } \\
\text { Parcialmente }\end{array}$ & $\begin{array}{c}\text { Atende } \\
\text { Parcialmente }\end{array}$ \\
\hline
\end{tabular}

Fonte: Dados da pesquisa (2019).

Sobre as informações disponibilizadas pelo Banco Bradesco em referência ao item 15.2.4.1 que trata da interação da entidade com o Meio Ambiente, mostra a criação do Programa Gestão da Ecoeficiência. 0 programa reúne um conjunto de ações e metas específicas acerca de temas como energia, água, papel, resíduos, plásticos e Gases do Efeito Estufa (GEE). 
No sentido de apoiar os funcionários no exercício da cidadania em atividades realizadas junto as comunidades, foi criado o Programa de Voluntariado; possuindo a finalidade de proporcionar oportunidades para atuarem de forma positiva na melhoria do meio ambiente e da qualidade de vida das comunidades nas quais estão inseridos, priorizando locais com maior carência social e ambiental.

Segundo as informações divulgadas em seus relatórios, é possível observar que sobre o meio ambiente houve uma sequência de projetos desenvolvidos que permaneceram em andamento. Percebe-se que nos anos de 2015 e 2016 o número de páginas nos dois relatórios foi maior comparado ao ano de 2017, sendo 142, 181 e 68 respectivamente. A redução no fluxo de informações também diminuiu.

\section{CONCLUSÃO}

Este estudo demonstra que, diante da evolução que o mercado financeiro vem obtendo nos últimos anos, as empresas estão adotando um perfil novo, diferenciado, que contribui com a sustentabilidade e assim venha receber novos investidores com retorno no longo prazo. Um questionamento que pode ser feito: Será que as empresas estão de fato interessadas em contribuir com a sociedade ou seria apenas uma estratégia de negócio? Porém, vale ressaltar que além das empresas e investidores, a sociedade e o meio ambiente também são favorecidos.

Conclui-se que, de forma geral, os objetivos foram atendidos. Vale ressaltar a importância destas informações para o mercado financeiro e seus investidores na busca por empresas apoiadoras da sustentabilidade.

Foi possível coletar os dados necessários para a realização da análise. Para as respostas, foram utilizados os termos "atende", para os quesitos que foram atendidos em sua totalidade, "atende parcialmente" quando suas respostas foram parcialmente respondidas e "não atende" quando não houve menção sobre o quesito apresentado.

O Banco Santander demonstrou perfil mais contemporâneo, voltou a atenção ao desenvolvimento corporativo, apoio aos estudantes universitários e desenvolvimento tecnológico como meio para o desenvolvimento de projetos sustentáveis.

O Banco do Brasil, empresa mista, controlada pela união, demonstrou perfil abrangente, considerando o mercado empresarial e público. 0 Banco Bradesco, demonstrou um perfil conservador, com estrutura sólida em seu longo tempo de atuação no mercado, presente em todos os municípios brasileiros.

Verificou-se que não houve menção sobre esta norma. Houve a utilização de outras metodologias para demonstrar suas informações como por exemplo o Instituto Brasileiro de Análises Sociais e Econômicas (IBASE) e a Global Reporting Initiative (GRI), Iniciativa Global de Informação.

Limitações foram encontradas no desenvolvimento do trabalho. Como, por exemplo, a ausência de algumas informações que causaram a classificação "não atende". Outras que foram relatadas de forma parcial e superficial, objetivando a divulgação do nome do Banco e não os dados referentes a sustentabilidade.

Diante de um processo de mudanças contínuas de comportamento humano, empresarial e inovação tecnológica, não é possível afirmar que este estudo seja classificado como conclusivo. Possivel- 
mente novos pesquisadores estarão em busca de acompanhar este e outros setores e obter resultados atualizados que contribuirão para o avanço das empresas no mercado de investimentos sustentáveis.

\section{REFERÊNCIAS}

BANCO BRADESCO S.A. Relatório de sustentabilidade-2019. Disponível em: https://www. bradescosustentabilidade.com.br/site/. Acesso em: 15 abr. 2019.

BANCO DO BRASIL S.A. Relatório Anual-2019. Disponível em: https://www.bb.com.br/docs.br/docs/ pub/siteEsp/ri/pt/dce/dwn/relan2017.pdf. Acesso em: 24 de abr. 2019.

BANCO SANTANDER. Relatório Anual-2019. Disponível em: https://www.ri.santander.com.br. Acesso em: 6 maio 2019.

BRAGA, Célia. Contabilidade ambiental: ferramenta para a gestão da sustentabilidade. São Paulo: Atlas, 2011.

CFC - Conselho Federal de Contabilidade. Resolução n 1.003/04 - Aprova a NBC 115 - Dispõe sobre informações de natureza social e ambiental. Brasília: CFC, 2004. Disponível em: http://cfc.org. br/sisweb/SRE/docs/Res_1003.pdf. Acesso em: 13 ago. 2018.

FERREIRA, A. C. S. Contabilidade ambiental: uma informação para o desenvolvimento sustentável. 3. ed. São Paulo: Atlas, 2011.

GERHARDT, T. E.; SILVEIRA, D. T. Métodos de pesquisa. UFRGS - Série educação a distância, 2009. Apostila.

GIL, A.C. Métodos e técnicas de pesquisa social. 6. ed. São Paulo: Atlas, 2008.

PAIVA, P. R. Contabilidade ambiental: evidenciação dos gastos ambientais com transparência e focada na prevenção. São Paulo: Atlas, 2003.

RIBEIRO, M. S. Contabilidade Ambiental. 2. ed. São Paulo: Saraiva, 2010.

TINOCO, J. E. P.; KRAEMER, M. E. P. Contabilidade e gestão ambiental. 3. ed. São Paulo: Atlas, 2011. 
1 Bacharel em Ciências Contábeis - CEULP/ULBRA. E-mail: neilafigueredo04@gmail.com

2 Doutora em Biotecnologia e Biodiversidade; Professora da Universidade Estadual do Tocantins - UNITINS. E-mail: coelho.ambiental@gmail.com

3 Doutora em Engenharia de Produção; Professora do CEULP/ULBRA - Curso de Ciências Contábeis. E-mail: contabeis@ceulp.edu.br

4 Mestre em Ensino; Professor do CEULP/ULBRA - Curso de Ciências Contábeis. E-mail: adriano131188@gmail.com

\section{(2) (1) (2)}

Este artigo é licenciado na modalidade acesso abertosob a Atribuição-Compartilhalgual CC BY-SA

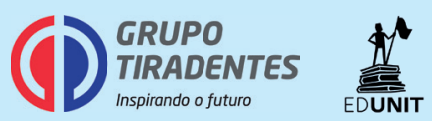

